\title{
Laparoscopic Treatment of Benign and Malignant Pelvic Disorders Utilizing Helium Plasma: A Retrospective Analysis
}

\author{
Michael R Manuel* \\ Cedars-Sinai Cancer, 18133 Ventura Blvd, Suite 300, Tarzana, CA, USA \\ *Corresponding author: Michael R Manuel, Cedars-Sinai Cancer, 18133 Ventura Blvd, Suite 300, Tarzana, CA, USA
}

\section{ARTICLE INFO}

Received: 豐 December 15, 2020

Published: 幽 December 23, 2020

Citation: Michael R Manuel. Laparoscopic Treatment of Benign and Malignant Pelvic Disorders Utilizing Helium Plasma: A Retrospective Analysis. Biomed J Sci \& Tech Res 32(5)-2020. BJSTR. MS.ID.005310.

Keywords: Helium Plasma; Laparoscopy; Pelvic Disorders; Retrospective; Laparotomy Conversion
ABSTRACT

Objective: Assess the clinical and surgical outcomes related to the use of helium plasma, a novel energy device, in the treatment of benign and malignant pelvic conditions.

Methods: Retrospective chart review of 110 patients who underwent a laparoscopic procedure for the treatment of benign and malignant pelvic conditions treated with helium plasma from May 1, 2015 to February 15, 2017. Data collection included patient demographics, operative details, conversion rate to laparotomy, and incidence of blood transfusion, hospital readmission, and adverse events.

Results: The mean age was $50.4 \pm 12.61$ years, and the mean body mass index was $30.6 \pm 6.95 \mathrm{~kg} / \mathrm{m}^{2}$. Medical comorbidity was noted in $52.7 \%$ of patients and $33.6 \% \mathrm{had}$ previous pelvic or gynecologic surgery. The mean surgical time was $94.5 \pm 33.68$ minutes. There were no conversions to laparotomy. The mean blood loss was $107.0 \pm 83.98 \mathrm{~mL}$ with one patient receiving a postoperative blood transfusion. There were no surgical site infections and one pelvic abscess occurred. There were no lymphedemas in patients undergoing lymph node dissection and no vaginal cuff dehiscence. The readmission rate was $0.9 \%$. No complications were noted.

Conclusions: Helium plasma was used successfully to treat patients with benign and malignant pelvic conditions, with no reported complications or conversions to laparotomy.

\section{Introduction}

When selecting the appropriate surgical approach for an individual patient, the surgeon considers many elements that can play a role in the choice of laparotomy or laparoscopy. These elements include patient-related factors (age, body habitus, and comorbidities) and surgical factors (duration of the operation, intraoperative complications, and lymph node yield) [1]. Multiple randomized controlled trials in general surgery, urology, and gynecology have established that laparoscopic surgery is less invasive and less painful than open surgery and is associated with faster recovery and fewer complications [2,3]. Additionally, trauma markedly affects the immune system, including both the specific and nonspecific immune response [4]. Probably the most successful way to reduce surgical trauma-induced immunosuppression is to reduce the extent of trauma and may imply the use of a minimally invasive approach $[5,6]$.
Complex gynecologic laparoscopy is an undertaking that requires careful dissection of pelvic structures. Conditions such as endometriosis, cancer, and fibroids can lead to anatomic abnormalities which can obscure important structures such as the bladder, ureters, and the serosal surfaces of the small and large intestine. In addition, previous surgery, such as Caesarean section, can lead to scarring between the uterus, adnexal structures, and the bladder. Many tools are available to facilitate laparoscopic surgery: vessel sealers, bipolar or unipolar-based cautery instruments, and ultrasonic dissectors. Some form of thermal energy is required to facilitate surgical dissections and key requirements of these instruments must include carefully controlled spread of thermal energy, ease of use, and effective tissue destruction. Existing surgical instruments can limit the surgeon's ability to negotiate around vital internal structures confidently. A concern with traditional 
electrocautery is controlling the energy spread. Previous studies comparing helium plasma to other energy sources such as $\mathrm{CO}_{2}$ laser demonstrated less or comparable lateral and depth of thermal spread for helium plasma in porcine peritoneum, bladder, and small intestine [7].

Helium plasma has been shown to be safe and effective in numerous surgical procedures where precise delivery of energy and minimal thermal spread to adjacent tissue are important, such as ablation of endometriotic cells on fallopian tubes and ovaries, and lysis of adhesions involving bowel or vital structures $[8,9]$. In a histology study on porcine small intestine, the helium plasma energy resulted in a depth of $0.334 \mathrm{~mm}$ of thermal effect compared to $1.8 \mathrm{~mm}$ for argon beam [7]. In further comparison, Sutton et al demonstrated that a monopolar pencil using highfrequency electrical current that is passed over the probe electrode to the tissue has a depth of reach of $4.75 \mathrm{~mm}$ with mean width of spread of $8.5 \mathrm{~mm}$ at settings of $20 \mathrm{~W} / 10 \mathrm{~W}$ pure coagulation [10]. This retrospective analysis was undertaken to evaluate the impact of helium plasma on patient outcome when treating benign and malignant pelvic conditions laparoscopically.

\section{Method}

\section{Study Patients}

This retrospective analysis was based on patient data collected at a single center from May 1, 2015 to February 15, 2017 (Dignity Health California Hospital Medical Center, Los Angeles, CA). Study oversight was provided by Northridge Hospital Regional IRB \#00002328 (Northridge, CA). The inclusion criterion was females aged 18-95 years who underwent a laparoscopic adhesiolysis procedure, lymph node dissection, and/or dissection of uterus and cervix for hysterectomy, for either benign or malignant pelvic conditions, using helium plasma (J-Plasma, Apyx Medical, FL)from May 1, 2015 to February 15, 2017.

\section{Surgical Approach}

Patients undergoing laparoscopic surgery in this study included patients with abnormal pelvic masses or other gynecologic cancers. Helium plasma was used for opening the retroperitoneum, dissecting the vesicouterine flap, and skeletonizing vascular structures prior to vessel sealing with another device. Helium plasma was also used for incision of the vaginal cuff and for separating the uterus/cervix from the vagina for hysterectomy. Lastly, helium plasma was used for the dissection of tissues, such as lymph nodes, from vessels. For patients with carcinomatosis or endometriosis, helium plasma was also used as-necessary for tissue ablation.

\section{Outcomes}

Patient variables collected were age, Body Mass Index (BMI), medical comorbidities, and previous pelvic or gynecologic surgery. Surgical variables included time in the operating room, total blood loss, complications, and conversion to laparotomy. Postoperative outcome variables were assessed up to 6 weeks after the surgery and included hospital length of stay and incidence of wound infection, blood transfusion, lymphedema, abscess, vaginal cuff dehiscence, reoperation, and hospital readmission.

\section{Results}

A total of 110 women who met the inclusion criterion and underwent a laparoscopic procedure for either benign or malignant pelvic disorders were included in this retrospective analysis. Demographics and baseline characteristics of all patients are presented in Table 1 . The mean age was $50.4 \pm 12.61$ years and $33.6 \%$ of patients had undergone previous pelvic or gynecologic surgery. The main preoperative diagnoses were ovarian neoplasm (34.5\%), endometrial cancer (21.8\%), and bleeding (13.6\%). The procedure was well tolerated with no conversion to laparotomy, no surgical complications and a very low incidence of postoperative events (Tables $2 \& 3$ ).

Table 1: Demographics and Baseline Characteristics.

\begin{tabular}{|c|c|}
\hline Characteristics & $N=110$ \\
\hline Age (years), mean \pm SD & $50.4 \pm 12.61$ \\
\hline $\mathrm{BMI}\left(\mathrm{kg} / \mathrm{m}^{2}\right)$, mean $\pm \mathrm{SD}$ & $30.6 \pm 6.95$ \\
\hline Medical comorbidities, n (\%) & $58(52.7)$ \\
\hline Previous pelvic or gynecologic surgery, n (\%) & $37(33.6)$ \\
\hline \multicolumn{2}{|l|}{ Preoperative diagnosis, n (\%) } \\
\hline ascites & $1(0.9)$ \\
\hline bleeding & $15(13.6)$ \\
\hline BRCA (prophylactic surgery) & $4(3.6)$ \\
\hline cervical cancer & $3(2.7)$ \\
\hline cervical dysplasia & $2(1.8)$ \\
\hline endometrial cancer & $24(21.8)$ \\
\hline endometrial hyperplasia & $5(4.5)$ \\
\hline endometriosis & $3(2.7)$ \\
\hline fibroids & $10(9.1)$ \\
\hline ovarian neoplasm & $38(34.5)$ \\
\hline ovarian cancer & $1(0.9)$ \\
\hline pelviv mass & $4(3.6)$ \\
\hline
\end{tabular}

Table 2: Surgical Operative Outcome.

\begin{tabular}{|c|c|}
\hline Outcome & $\mathbf{N}=\mathbf{1 1 0}$ \\
\hline Operating room time (minutes), mean \pm SD & $94.5 \pm 33.68$ \\
\hline Blood loss (mL), mean \pm SD & $107.0 \pm 83.98$ \\
\hline Conversion to laparotomy, $\mathrm{n}$ & 0 \\
\hline Complications, $\mathrm{n}$ & 0 \\
\hline
\end{tabular}

Table 3: Postoperative Outcome (Up to 6 Weeks).

\begin{tabular}{|c|c|}
\hline Outcome $^{\mathbf{a}}$ & $\mathbf{N}=\mathbf{1 1 0}$ \\
\hline Hospitalization (days), mean \pm SD & $1.0 \pm 0.93$ \\
\hline Blood transfusion & $1(0.9 \%)$ \\
\hline
\end{tabular}




\begin{tabular}{|c|c|}
\hline Surgical site infection & 0 \\
\hline Abscess & $1(0.9 \%)$ \\
\hline Vaginal cuff dehiscence & 0 \\
\hline Lymphedema & 0 \\
\hline Readmission & $1(0.9 \%)$ \\
\hline Reoperation & $1(0.9 \%)$ \\
\hline \multirow{2}{|c|}{ anless mentioned otherwise, data are presented as number of event } \\
and frequency, n (\%)
\end{tabular}

\section{Discussion}

This retrospective study was designed to assess the value of helium plasma, which does not use conductive currents, for reducing patient morbidity when treating benign and malignant pelvic pathology. The absence of surgical complications and conversion to laparotomy, and the very limited number of postoperative events, suggests that this device may have value for the laparoscopic surgeon. The strengths of this study are the sample size and the variability of disease treated, as patient selection was not limited by age, BMI, or the presence of malignancy. The limitation of this study is its retrospective nature, and randomized prospective trials will be necessary to validate universal acceptance of these findings and adoption of this promising new technology.

\section{Conclusion}

Helium plasma is a novel modality for the minimally invasive surgeon and was used in this study successfully for laparoscopic treatment of benign and malignant pelvic conditions, with no complications or conversion to laparotomy.

\section{Conflict of Interest}

Dr. Manuel reports grants from Apyx Medical (formely Bovie Medical) to the Institution to cover IRB fees and study administration and personal fees as consultant during the conduct of the study and for writing the manuscript.

\section{Acknowledgement}

The author wants to thank Craig E. McCoy, DO, for his assistance in the drafting of the manuscript, and Ms. Annie Levesque, MSc, for her assistance with the editing of the manuscript. Dr McCoy and Ms Levesque received a payment from Apyx Medical for their work.

\section{Author Contribution}

Dr Manuel was the study investigator and critically revised and approved the manuscript.

\section{References}

1. Hauspy J, Jimenez W, Rosen B, Gotlieb WH, Fung Kee Fung M, et al. (2010) Laparoscopic surgery for endometrial cancer: a review. J Obstet Gynaecol Can 32(6): 570-579.

2. Kluivers KB, Hendriks JC, Mol BW, Bongers MY, Bremer GL, et al. (2007) Quality of life and surgical outcome after total laparoscopic hysterectomy versus total abdominal hysterectomy for benign disease: a randomized, controlled trial. J Minim Invasive Gynecol 14(2): 145-152.

3. Burgess NA, Koo BC, Calvert RC, Hindmarsh A, Donaldson PJ, et al. (2007) Randomized trial of laparoscopic v open nephrectomy. J Endourol 21(6): 610-613.

4. Menger MD, Vollmar B (2004) Surgical trauma: hyperinflammation versus immunosuppression? Langenbecks Arch Surg 389(6): 475-484.

5. Wildhirt SM, Schulze C, Schulz C, Egi K, Brenner P, et al. (2001) Reduction of systemic and cardiac adhesion molecule expression after off-pump versus conventional coronary artery bypass grafting. Shock 16(Suppl 1): 55-59.

6. Decker D, Springer W, Decker P, Tolba R, Remig J, et al. (2003) Changes in TH1/TH2 immunity after endovascular and conventional infrarenal aortic aneurysm repair: its relevance for clinical practice. Eur J Vasc Endovasc Surg 25(3): 254-261.

7. Pedroso J, Gutierrez M, Volker W (2014) J-Plasma, monopolar pencil, argon beam and $\mathrm{CO}_{2}$ laser electrosurgery: comparative evaluation of thermal spread in a porcine tissue model (white paper). Bovie Medical Corporation.

8. McCoy CE. Novel surgical approach targeting chronic pelvic pain with J-Plasma (white paper). Bovie Medical Corporation.

9. McCoy CE. Treating endometriosis and chronic pelvic pain with J-Plasma (white paper). Bovie Medical Corporation.

10. Sutton C, Abbott J (2013) History of power sources in endoscopic surgery. J Minim Invasive Gynecol 20(3): 271-278.

\section{ISSN: 2574-1241}

DOI: $10.26717 /$ BJSTR.2020.32.005310

Michael R Manuel. Biomed J Sci \& Tech Res

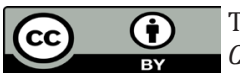

This work is licensed under Creative Commons Attribution 4.0 License

Submission Link: https://biomedres.us/submit-manuscript.php

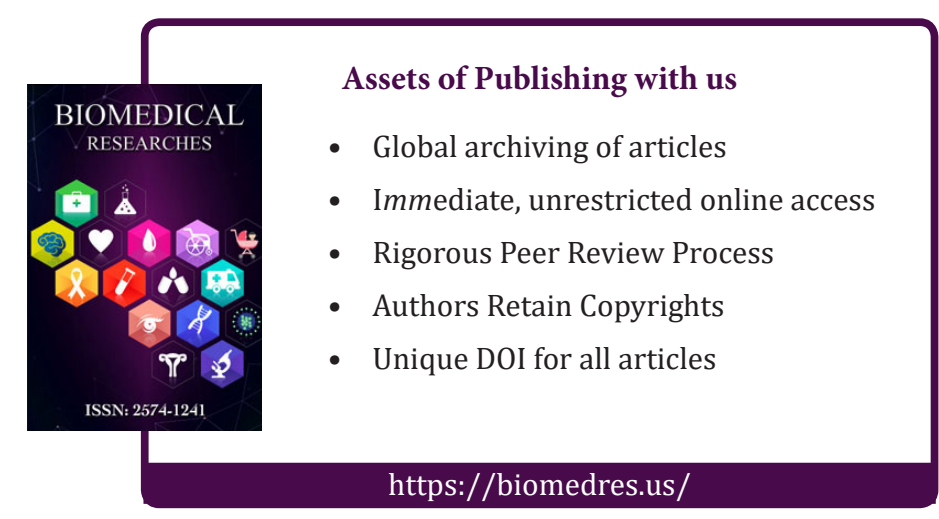

